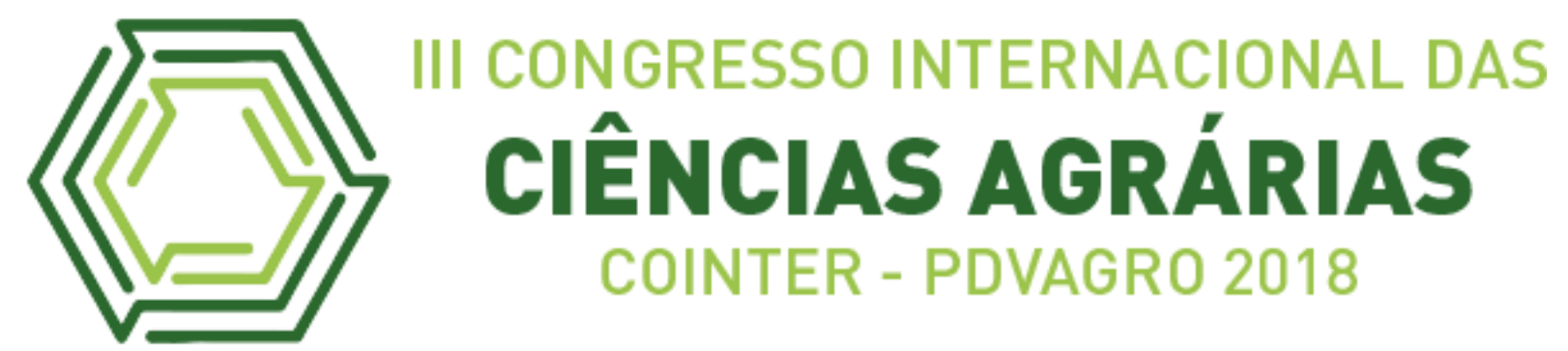

\title{
COMERCIALIZAÇÃO DA CARNE SUÍNA NO MUNICÍPIO DE PASSIRA
}

\section{MARKETING OF PORK IN THE MUNICIPALITY OF PASSIRA}

\author{
Apresentação: Pôster \\ Amanda Karolaine Lima da Silva ${ }^{1}$; Max Jefferson da Silva Nascimento ${ }^{2}$; Marta Xavier de \\ Carvalho Correia ${ }^{3}$
}

\section{DOI: https://doi.org/10.31692/2526-7701.IIICOINTERPDVAGRO.2018.00379}

\section{Introdução}

Pesquisas apontam que a carne suína é vista, de forma errônea, como gordurosa e prejudicial. Na verdade, ela é rica em nutrientes necessários ao corpo humano e, quando consumida sem exageros, não causa nenhum dano à saúde (SARCINELLI et al., 2007). Nessa perspectiva, compete a todos os elos da cadeia produtiva mudar a imagem da carne suína, de não saudável, gorda e com alto colesterol, para uma carne saudável, e com proteína de alta qualidade, oriunda de criações com manejo compatível com as normas de bem-estar animal (MACHADO FILHO, 2000).

A proteína da carne suína contribui para o bom funcionamento do organismo e sua qualidade está relacionada, além da genética, ao manejo dos animais, alimentação, higienização e manejo pré-abate realizados de forma correta. Porém, apesar de todo rigor com os cuidados na criação e abate, a forma como ela é comercializada pode afetar todo o trabalho realizado na granja, pois quando a carne não é armazenada de forma adequada, vai ocorrer contaminação e, também, através de uma manipulação não higiênica como também a presença de insetos e microrganismo podem comprometer a saúde do consumidor.

A alimentação disponível para o consumo da população não pode estar submetida a qualquer tipo de risco por contaminação (SILVA, 2012). As enfermidades de origem alimentar ocorrem quando uma pessoa contrai uma doença por ingestão de alimentos contaminados com microrganismos ou toxinas indesejáveis (SOUZA, 2004).

\footnotetext{
${ }^{1}$ Zootecnia, IFPE - INSTITUTO FEDERAL DE PERNAMBUCO, amandalimaazul@gmail.com

${ }^{2}$ Zootecnia, IFPE - INSTITUTO FEDERAL DE PERNAMBUCO, maxjefferson388@gmail.com

${ }^{3}$ Professora Dra a IFPE - INSTITUTO FEDERAL DE PERNAMBUCO, marta.xavier@vitoria.ifpe.edu.br
} 
A cidade está localizada no estado de Pernambuco na região agreste e tem aproximadamente 28.000 habitantes onde a sua maioria trabalham em cidades maiores e alguns desenvolvem atividades como pequenos produtores. Nesta perspectiva, objetivou-se investigar as condições em que a carne suína é comercializada no município de Passira.

\section{Fundamentação Teórica}

O mercado da carne suína tem apresentado no Brasil um crescimento contínuo, passando este produto a ter uma maior participação na dieta dos brasileiros. Estes consumidores, no entanto, tornam-se cada vez mais preocupados em obter um alimento dentro dos padrões higiênico-sanitários vigentes (RODRIGUES et al., 2009).

A carne suína, tem composição muito semelhante as demais e ao contrário do que muitos pensam, é um alimento rico em nutrientes, apresentando diversos benefícios indiscutíveis à saúde humana (SARCINELLI et al., 2007), por conter substancias necessárias para um bom funcionamento do organismo.

O mito de que a carne suína é gordurosa e faz mal à saúde é um fato que precisa ser sanado. A carne é um dos alimentos de grande importância na dieta do homem por possuir propriedades especificas, como proteínas de alto valor biológico por possuir todos os aminoácidos essenciais para o organismo e alta digestibilidade (MAGNONI e PIMENTEL, 2007). Muitas pessoas desconhecem estas informações, e geram alguns conceitos equivocados, esquecendo que além de saborosa, ela é também saudável (GEESDORF, 2010).

Os alimentos podem ser contaminados na sua manipulação ou no próprio ambiente em que foram produzidos e comercializados (SILVA, 2012). A incorreta manipulação, conservação e o descuido em relação às normas higiênicas favorecem a contaminação do produto por microrganismos patogênicos (MELLO et al., 2010). Para que se evite uma contaminação da carne, a mesma tem que ser armazenada de forma adequada em câmara frigorífica ou freezer e geladeiras preservando-a assim contra a presença de microrganismos.

\section{Metodologia}

Foram observados os pontos de comercialização da carne suína na cidade de Passira, município de Pernambuco. Por ser uma cidade pequena as feiras ocorrem semanalmente nas sextas e sábados. O comércio de carnes nesta cidade é realizado no mercado público que é coberto e tem boxes individuais, nos quais cada comerciante expõe sua mercadoria e em supermercados.

A partir de observação e alguns questionamentos aos comerciantes de carne suína, coletamos dados para o estudo deste trabalho. Levantou-se dados sobre aspectos da 
comercialização de carne na cidade, tais como preço do produto, a origem do animal e conhecimentos sobre boas práticas de manipulação do produto e higienização a fim de garantir uma boa qualidade da mercadoria sem que interfira na saúde do consumidor.

\section{Resultados e Discussões}

De forma geral, observou-se que os comerciantes são da própria cidade e em sua maioria são homens. No mercado público a carne suína o preço do produto era em torno de $\mathrm{R} \$ 10,00$ $\mathrm{kg}$, na maioria comprada de pequenos produtores locais.

Em relação ao manuseio da carne e higienização do ambiente de comercialização, percebeu-se que os manipuladores estavam sem gorro, luvas e avental e tinha contato com dinheiro, apresentavam-se suados e a faca usada nos cortes da carne estava suja de sangue o que, consequentemente, em conjunto com os outros fatores, aumentam a possibilidade de contaminação da carne com algum tipo de microrganismo gerando o risco de desenvolvimento de doenças ao consumidor.

A carne estava exposta em cima da bancada (Imagem 1 e 2), confeccionada de madeira, material de difícil desinfecção, e pendurada em ganchos de inox, estavam sem nenhuma refrigeração, em relação às medidas de higiene dos utensílios e equipamentos utilizados no beneficiamento da carne, realizavam sua limpeza apenas com um pano, esta era também utilizada na limpeza das bancadas e secagem das mãos. Segundo a RDC no 216 (BRASIL, 2004), as operações de higienização dos utensílios e equipamentos devem ser realizadas com frequência que garanta a manutenção dessas condições e minimize o risco de contaminação do alimento apresentando que as condições de comercialização não estão de acordo com essa normativa.

No local havia insetos e alguns animais domésticos como cães e gatos que circulavam no mercado público, tinha lixeiras abarrotadas muito próximas aos boxes.

Imagens 1 e 2: Comercialização da carne suína no Mercado Público de Passira. Fonte: própria.
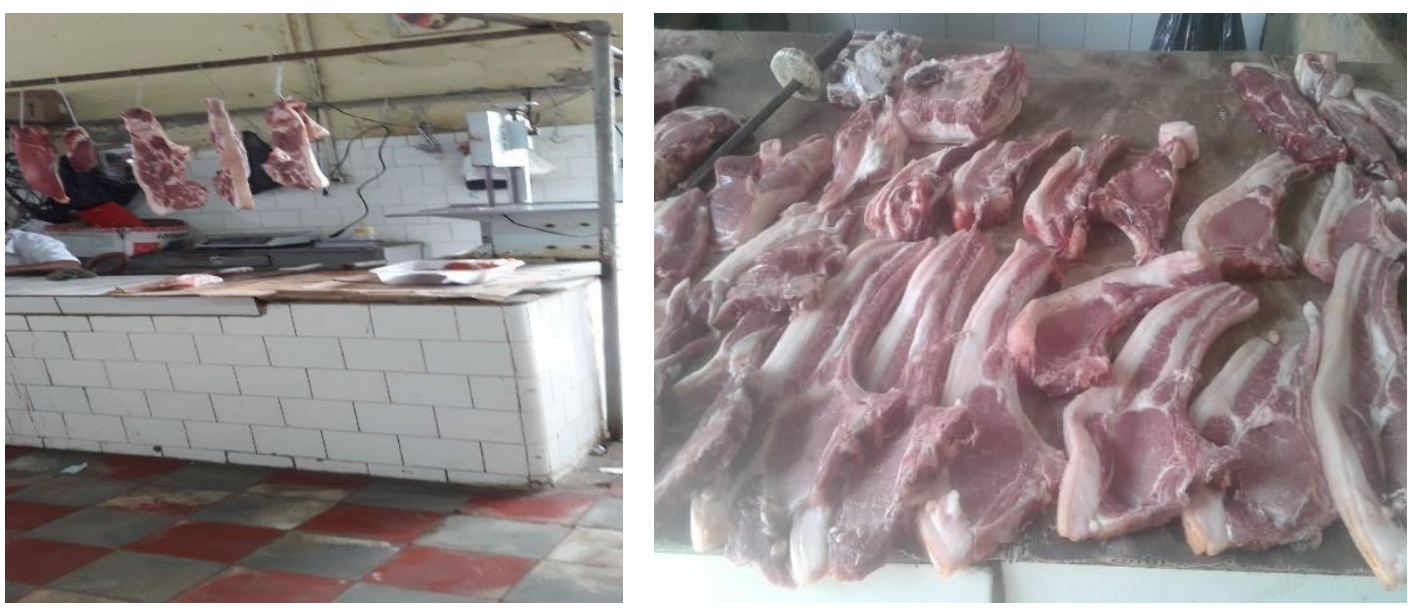
Percebe-se que a carne suína comercializada no mercado público de Passira apresenta resultados semelhantes aos obtidos por Coutinho et al. (2007) que ao estudarem as feiras de Solânea e Bananeiras na Paraíba, concluíram que as carnes comercializadas são expostas sob condições precárias de higiene, e manipuladas por comerciantes que negligenciam a higiene pessoal e as boas práticas de manipulação. Quando a carne comercializada é exposta em ambientes em que não há algum tipo de higienização e boas práticas de manipulação isso comprometerá na sua qualidade pelo fato de a falta de higienização contaminar a carne de algum modo através de bactérias e microrganismos interferindo na boa saúde do consumidor.

Quando avaliado o supermercado, observou-se que a carne era vendida com maior preço, em média o quilograma por $\mathrm{R} \$ 12,00$ e o animal vem de empresas distribuidoras, já em cortes comerciais e com selos que identificam a empresa fornecedora do produto. Foi observado neste local que o manipulador estava com botas, gorro, luvas de látex e avental, a serra elétrica e a faca utilizada para cortar a carne estavam aparentemente limpas. No ambiente não havia a presença de animais ou insetos, a carne estava armazenada em freezers e isto, consequentemente contribui para uma boa manutenção da qualidade do produto (Imagem $3)$.

Imagem 3: Comercialização da carne suína no supermercado.

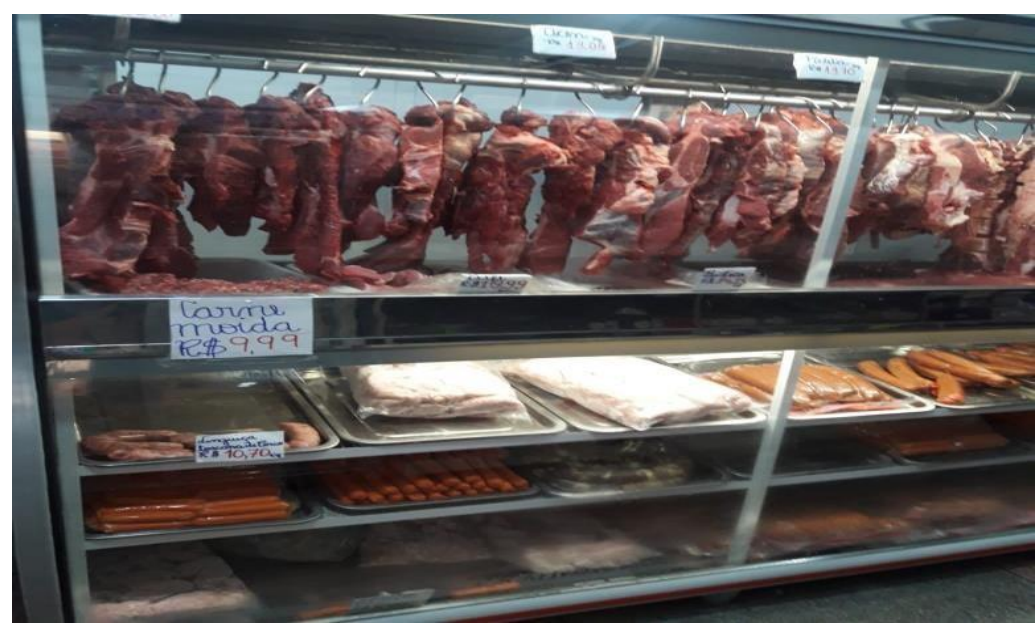

Comparando esses locais em que a carne é vendida no município, percebe-se que há uma grande diferença na qualidade do produto vendido, uma vez que quando a carne está armazenada em boas condições e com boas práticas de higienização contribui para uma diminuição de riscos de contaminação da mesma, visto que, a manipulação e o armazenamento estavam aparentemente agradáveis ao olhar do consumidor. Percebe-se também uma diferença entre os preços médios nos locais em que ela é vendida mostrando, nesse caso, certa 
diferenciação da qualidade porque onde ela é mais barata o local não se encontra em boas qualidades para armazenamento e manutenção do produto.

\section{Conclusões}

A comercialização da carne feita no mercado público do município onde foi desenvolvido este trabalho encontra-se em desacordo com a legislação, não sendo a mais indicada para o consumidor devido à possibilidade de contaminação do produto, porem ocorre normalmente não se sabe se por negligencia ou desinformação dos envolvidos no processo. $\mathrm{O}$ ponto de venda mais indicado é o varejo pelo fato de este local apresentar o produto em condições, aparentemente, fora do alcance de bactérias que prejudiquem a qualidade do produto e a saúde do consumidor.

É preciso que haja uma maior fiscalização sanitária no mercado público do município para que as carnes vendidas neste local não estejam submetidas a exposição de um ambiente propício ao desenvolvimento de bactérias e microrganismos que venham porventura, comprometer a saúde do consumidor. É necessária uma reestruturação dos locais de comercialização, como também um trabalho de orientação dos comerciantes e consumidores sobre o manuseio de produtos alimentícios.

\section{Referências}

BRASIL. 2004. Ministério da Saúde. Agência Nacional de Vigilância Sanitária. Resolução RDC n ${ }^{\circ} 216$, de 15 de setembro de 2004. Dispõe sobre o regulamento técnico de boas práticas para serviços de alimentação. Diário Oficial [da] República Federativa do Brasil, Brasília, 16 set. 2004. p. 1-10.

COUTINHO, E. P.; OLIVEIRA, A. T.; FRANCISCO, M. S.; SILVA, M. J.; SILVA, J. M. S.; AZEREDO, L. P. M. 2007. Avaliação das condições higiênico-sanitárias da manipulação e comercialização de carnes vermelhas e aves nas feiras livres dos municípios de Bananeiras e Solânea, PB. In: II Jornada Nacional de Agroindústria. Bananeiras - PB. Anais... Paraíba.

GEESDORF, C. Benefícios da carne suína na alimentação humana, Portal Dia de Campo, 2010.

MACHADO FILHO, L.C.P. Bem-estar de suínos e qualidade da carne: uma visão brasileira. In: I CONFERÊNCIA INTERNACIONAL VIRTUAL SOBRE QUALIDADE DE CARNE SUÍNA, 2000, Concórdia. Anais Concórdia: Embrapa, 2000. p. 34-40.

MAGNONI, D; PIMENTEL, I. A Importância da Carne Suína Na Nutrição Humana. São Paulo: UNIFEST, 2007. 
MELlO, A. G.; GAMA, M. P.; MARIN, V. A.; COLARES, L. G. T. Conhecimento dos manipuladores de alimentos sobre boas práticas nos restaurantes públicos populares do Estado do Rio de Janeiro. Brazilian Journal of Food Technology, v.13, n. 1, p. 6068. 2010.

RODRIGUES, G.Z.; GOMES, M.F.M.; CUNHA, D.A.; SANTOS, V.F. Evolução da produção de carne suína no Brasil: uma análise estrutural-diferencial. Revista de Economia e Agronegócio. v.6, n.3, p. 343-366, 2009.

SARCINELli, M.F.; VENTURINI, K.S.; SILVA, L.C.: Características da Carne Suína, Universidade Federal do Espírito Santo - UFES, 2007.

SILVA, R. A; Ciência do Alimento: Contaminação, Manipulação e Conservação dos Alimentos. Dissertação. Universidade Tecnológica Federal do Paraná, Diretoria de Pesquisa e Pós-Graduação, Especialização em Ensino de Ciências, 2012.

SOUZA, S. S. Alimentos seguros: orientações técnicas. São Paulo: Secretaria Municipal de Saúde, 2004. 